\title{
Structural Studies on the O-Specific Side-Chains of the Cell-Wall Lipopolysaccharide from Salmonella strasbourg
}

\author{
CARL GUSTAF HELLERQVIST, BENGT LINDBERG and \\ AKE PILOTTI
}

\begin{abstract}
Institutionen för organisk kemi, Stockholms Universitet, Stockholm, Sweden
\end{abstract}
ALF A. L IN D B ERG

Statens bakteriologiska laboratorium, Stockholm, Sweden

\begin{abstract}
The structure of the O-specific side-chains of the Salmonella strasbourg $(\mathbf{9 , 4 6})$ lipopolysaccharide (LPS) has been investigated. Previous studies demonstrating the partial structure (I) of the chemical repeating unit have been confirmed. It was further demonstrated that $\mathrm{D}$-galactose is the terminal reducing sugar residue of the biological repeating unit, and that the tyvelose and $\mathrm{L}_{\mathrm{L}}$-rhamnose residues are $\alpha$-linked. The presence of a terminal D-glucose residue, linked to D-galactose in the 4-position, in a small part of the repeating units, is indicated.
\end{abstract}

Structural studies on the lipopolysaccharide (LPS) from Salmonella strasbourg $N_{(9,46)}$, belonging to group $D_{2}$, were recently reported by Staub $^{1}$ and coworkers and a detailed structure (I) of the chemical repeating unit of the $\mathrm{O}$-specific side-chains was proposed.

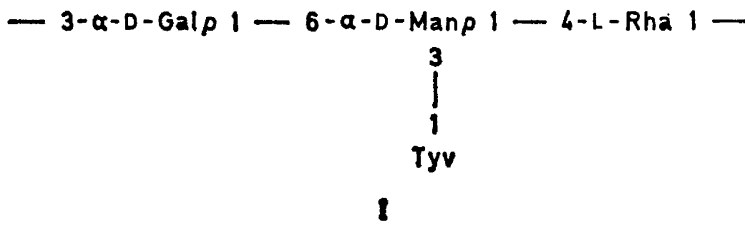

Graded acid hydrolysis, followed by isolation and identification of oligosaccharides, was the principal method used in these studies. Some complementary evidence was obtained by periodate studies. 
In our studies on Salmonella LPS, e.g. those from the group $\mathrm{D}_{1}{ }^{2}$ we use different methods, essentially based upon methylation analysis of the LPS and of chemically modified LPS. With these methods, which give quantitative results, it is often possible to obtain more detailed information than with graded acid hydrolysis and characterisation of oligosaccharides. In the present paper, such studies on the LPS from S. strasbourg I. S. 627 are reported.

\section{ISOLATION OF THE LIPOPOLYSACCHARIDE}

The LPS was isolated from bacterial cell walls of $S$. strasbourg $(9,46)$ by extraction with phenol-water. ${ }^{3}$ It was demonstrated by passive hemaglutination inhibition that the LPS inhibited $0 ; 9,0 ; 12_{3}$, and $0 ; 46$ factor sera.

A two step acid hydrolysis ${ }^{4}$ of the I.PS yielded tyvelose, I-rhamnose, $\mathrm{D}$-mannose, $\mathrm{D}$-galactose, $\mathrm{D}$-glucose, and a heptose in the relative proportions 18:18:19:27:9:8. The first three sugars occur only in the $\mathrm{O}$-specific side-chains whereas D-galactose, D-glucose, and heptose are assumed to be part of the basal core in equal amounts. In this study the sugars were analysed by GLC $^{5}$-mass spectrometry ${ }^{6}$ as their alditol acetates. In previous studies ${ }^{7}$ these sugars were fully identified.

On treatment of the LPS with methanolic hydrogen chloride and separation of the methanolysate products by GLC no methyl acetate was observed, demonstrating that this LPS does not contain $O$-acetyl groups.

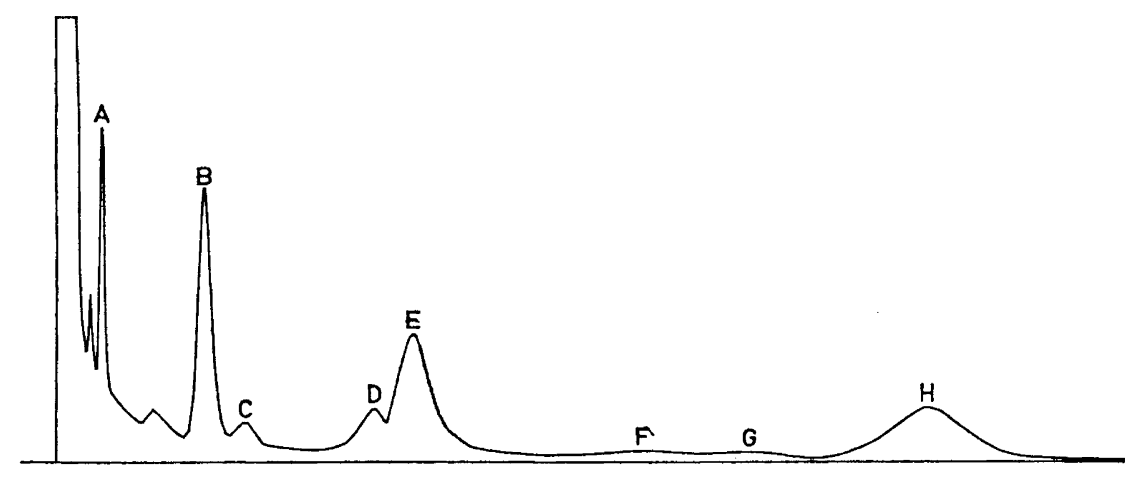

Fig. 1. GLC separation of methylated sugars, as their alditol acetates, obtained from the hydrolysate of the fully methylated lipopolysaccharide.

\section{METHYLATION ANALYSIS OF THE LIPOPOLYSACCHARIDE}

The LPS was methylated by treatment with methyl sulphinyl sodium and methyl iodide in methyl sulphoxide. ${ }^{8}$ The fully methylated LPS was hydrolysed into a mixture of methylated sugars, which were analysed as their alditol acetates by GLC $^{9}$-mass spectrometry. ${ }^{10}$ A typical GLC on an ECNSS-M column is given in Fig. 1. The results of the methylation analysis are summarized in Table 1 . 
Table 1. Methyl ethers from the hydrolysate of methylated lipopolysaccharide.

\begin{tabular}{|c|c|c|c|}
\hline Sugars & Peak & $T^{a}$ & $\operatorname{mol} \%^{b}$ \\
\hline 2,4-Di- $O$-methyl-tyvelose & $\mathbf{A}$ & 0.29 & 9.1 \\
\hline 2,3-Di-O-methyl-L-rhamnose & $\mathbf{B}$ & 0.98 & 18.8 \\
\hline 2,3,4,6-Tetra- $O$-methyl-D-glucose & B & 1.00 & 1.1 \\
\hline $\mathbf{2 , 3 , 4 , 6}$-Tetra- $O$-methyl-D-galactose & $\mathbf{C}$ & 1.25 & 2.7 \\
\hline 3,4,6-Tri-O-methyl-D-glucose & $\mathrm{D}$ & 1.98 & 1.5 \\
\hline 2,4,6-Tri- $O$-methyl-D-mannose & $\mathrm{D}$ & 2.08 & 2.5 \\
\hline 2,4,6-Tri- $O$-methyl-D-galactose & $\mathrm{E}_{1}$ & 2.25 & 21.2 \\
\hline 3,4,6-Tri-O-methyl-D-galactose & $\mathbf{E}_{\mathbf{2}}$ & 2.50 & 1.5 \\
\hline 2,6-Di- $O$-methyl-D-galactose & $\bar{F}$ & 3.62 & 1.2 \\
\hline 3,6-Di-O-methyl-D-galactose & $\mathrm{G}$ & 4.30 & 1.8 \\
\hline 2,4-Di-O-methyl-D-glucose & $\mathrm{H}_{1}$ & 5.10 & 2.7 \\
\hline 2,4-Di-O-methyl-D-mannose & $\mathrm{H}_{2}$ & 5.35 & 20.0 \\
\hline
\end{tabular}

a Retention times of the corresponding alditol acetates on the ECNSS - M column relative to 1,5-di-O-acetyl-2,3,4,6-tetra- $O$-methyl-D-glucitol.

${ }^{b}$ As a considerable amount of 2,4-di- $O$-methyl-tyvelose was lost during the methylation analysis, the mol \% of the methylated sugars are given relative to that of 2,3-di- $O$-methyl-L rhamnose, which, it is assumed, represents the mol \% of L-rhamnose in the original lipopoly. saccharide.

Some of the peaks on the GLC were well resolved and the identifications of the components in these peaks by their mass spectra and $T$-values (retention times relative to the alditol acetate derived from 2,3,4,6-tetra-O-methylD-glucose) require no comments.

Peak $\mathrm{B}$ contained the alditol acetates derived from 2,3-di- $O$-methyl-Lrhamnose $(T=0.98)$ and $2,3,4,6$-tetra- $O$-methyl-D-glucose $(T=1.00)$ which were fully resolved on a polyphenyl ether column. The latter separation also revealed the absence of the 2,3,4,6-tetra- $O$-methyl-D-mannose derivative $(T=1.00$ on the ECNSS column) in peak B.

Peak D on the GLC-figure seems to contain only one component. It was, however, better resolved into two peaks at $140^{\circ}$. These were identified by $T$-values and mass spectra as deriving from 3,4,6-tri- $O$-methyl-D-glucose and 2,4,6-tri- $O$-methyl-D-mannose.

The shape of peak $\mathrm{E}$ indicates the presence of a major component $\mathrm{E}_{1}$ $(T=2.28)$ which partially overlaps a minor component $\mathrm{E}_{2}(T=2.5)$. The major component, by its mass spectra and $T$-values, was identified as being derived from 2,4,6-tri- $O$-methyl-D-galactose, and the minor component, by similar arguments, as being derived from 3,4,6-tri- $O$-methyl-D-galactose $(T=2.50)$.

The shape of peak $\mathrm{H}$ indicates the presence of a major component $\mathrm{H}_{2}$, $(T=5.35)$, and a minor component $\mathrm{H}_{1}(T=5.1)$. Mass spectra of different parts of peak $\mathrm{H}$ all gave the spectrum for a 2,4-di- $O$-methyl-hexose derivative. From the $T$-values of the corresponding $\mathrm{D}$-glucose, $\mathrm{D}$-galactose, and $\mathrm{D}$-mannose derivative, $5.10,6.35$, and 5.35 , respectively, the components were identified 
as being derived from 2,4-di-O-methyl-D-glucose $\left(\mathrm{H}_{1}\right)$ and 2,4-di-O-methyl-Dmannose $\left(\mathrm{H}_{2}\right)$.

The LPS was subjected to a mild acid hydrolysis, and as anticipated this led to preferential cleavage of all the tyvelosidic linkages. The oligoand polymeric material was recovered by gel filtration and subjected to methylation analysis. The results, given in Table 2, demonstrate that all tyvelose has disappeared and that all the 2,4-di- $O$-methyl-D-mannose has been replaced by 2,3,4-tri- $O$-methyl-D-mannose. In addition, the percentage of 2,4,6-tri- $O$-methyl-D-galactose decreased and a corresponding increase in 2,3,4,6-tetra- $O$-methyl-D-galactose was observed.

Table 2. Methyl ethers from the hydrolysate of methylated, degraded lipopolysaccharide.

\begin{tabular}{|l|r|r|}
\hline \multicolumn{1}{|c|}{ Sugars } & $T^{a}$ & mol $\%^{b}$ \\
\hline 2,3-Di-O-methyl-L-rhamnose & & \\
2,3,4,6-Tetra-O-methyl-D-glucose & 0.98 & 18.8 \\
2,3,4,6-Tetra-O-methyl-D-galactose & 1.00 & 1.1 \\
2,4,6-Tri-O-methyl-D-galactose & 1.25 & 11.1 \\
2,3,4-Tri-O-methyl-D-mannose & $\mathbf{2 . 2 5}$ & $\mathbf{9 . 1}$ \\
\hline
\end{tabular}

See Table 1.

$b$ The mol \% of the methylated sugars are given relative to that of 2,3-di- $O$-methyl-L-rhamnose, which, it is assumed, represents the mol \% of L-rhamnose in the original lipopolysaccharide.

\section{PARTIAL ACID HYDROLYSIS OF THE LPS}

A solution of the LPS in $0.15 \mathrm{M}$ sulphuric acid was kept at $80^{\circ}$, and the change in optical rotation was followed (Fig. 2). The curve is similar to that obtained on hydrolysis of the $S$. typhi and $S$. enteritides LPS, and indicates, by the same arguments as used in the discussion of these results, ${ }^{2}$ that the tyvelose residues are $\alpha$-linked and the L-rhamnosidic linkages $\alpha$-linked.

Fig. 2. Optical rotation versus time on acid hydrolysis of lipopolysaccharide.

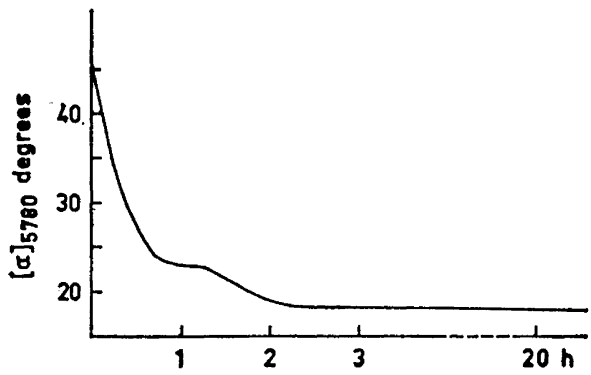




\section{DISCUSSION}

Monosaccharide analyses of the LPS show that the repeating unit of the 0 specific side-chains contains one residue each of tyvelose, L-rhamnose, D-mannose, and $\mathrm{D}$-galactose. Some of the minor components obtained in the methylation analysis, viz. 2,3,4,6-tetra- $O$-methyl-D-galactose, 3,4,6-tri- $O$-methyl-D-glucose, 3,4,6-tri- $O$-methyl-D-galactose, 3,6-di-O-methyl-D-galactose, and 2,4-di-Omethyl-D-glucose, were most likely derived from the core part of the LPS.

The methyl ethers of tyvelose, L-rhamnose, D-mannose, and the major $\mathrm{D}$-galactose derivative, 2,4,6-tri- $\mathrm{O}$-methyl-D-galactose, arise from the $\mathrm{O}$-specific side-chains. The structural significance of the minor components: 2,3,4,6tetra- $O$-methyl-D-glucose and 2,6-di-O-methyl-D-galactose is less obvious and will be discussed below.

The methylated derivatives obtained showed that tyvelose, D-mannose, and D-galactose exist in pyranose form. As to rhamnose, the only derivative obtained was 2,3-di-O-methyl-L-rhamnose, and this could derive from either pyranose or furanose residues. However, since rhamnose residues of the LPS were less readily hydrolysed than would be expected had they-been furanosidic,

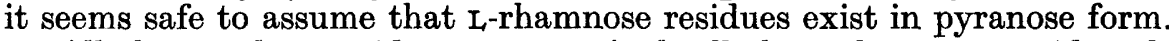

All the tyvelose residues are terminal, all the L-rhamnose residues linked in the 4-position, and all the D-galactose residues in the $\mathrm{O}$-specific side-chains are linked in the 3-position. Most of the D-mannose residues are branching points, linked in the 3- and 6-positions.

In the methylation analysis of the partially hydrolysed LPS, as opposed to the original LPS, 2,4-di- $O$-methyl-tyvelose and 2,4-di- $O$-methyl-D-mannose were no longer detected. Instead 2,3,4-tri-O-methyl-D-mannose was found, showing that tyvelose is linked to $\mathrm{D}$-mannose in the 3-position in the original LPS. Further, the percentage of 2,4,6-tri- $O$-methyl-D-galactose was decreased and a corresponding increase in 2,3,4,6-tetra- $O$-methyl-D-galactose was observed. As the L-rhamnosidic linkage is the second most readily hydrolysed in the $\mathrm{O}$-specific side-chains, this demonstrates that $\mathrm{L}_{1}$-rhamnose is linked to D-galactose in the original LPS.

From the preceding arguments, the linkages and the sequence of the sugar residues in the repeating units are determined. The results are in complete agreement with the structure proposed by Staub and coworkers ${ }^{1}$ (I). These authors also determined the anomeric nature of the $\mathrm{D}$-mannose and $\mathrm{D}$-galactose residues as $\alpha$. We have demonstrated by partial hydrolysis and polarimetry that the tyvelose and the L-rhamnose residues are $\alpha$-linked.

The 2,4,6-tri-O-methyl-D-mannose obtained in the methylation analysis of the undegraded LPS almost certainly derives from those 3-O- $\alpha$-tyvelosido$\mathrm{D}$-mannose residues, which are the end groups of the $\mathrm{O}$-specific side chains. Therefore, $\mathrm{D}$-galactose is the terminal reducing sugar residue of the biological repeating unit (II). Analogous results have been obtained by biochemical or chemical methods for LPS from different Salmonella groups: $\mathrm{B},{ }^{4,11,12} \mathrm{D}^{, 2}$ and E. ${ }^{13}$ From the relative proportion of 2,4,6-tri- $O$-methyl-D-mannose and of 2,4-di-O-methyl-D-mannose, the average number of repeating units in the side-chains is estimated to be about 10 . 


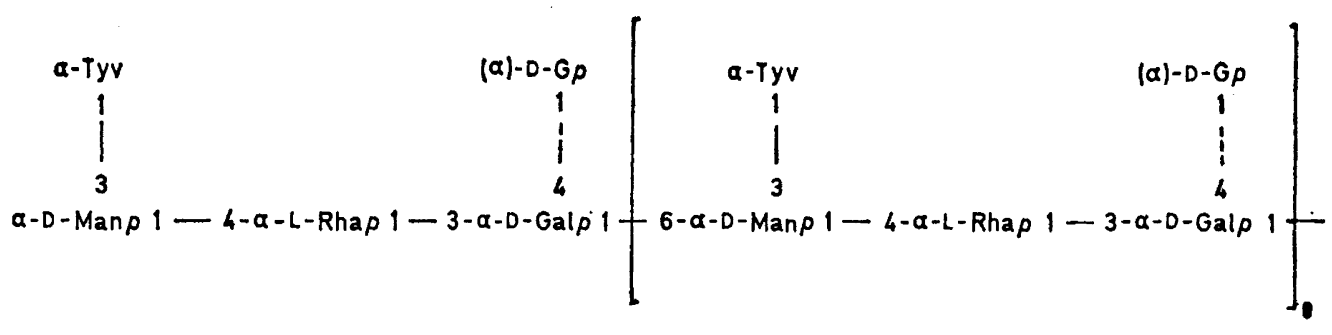

II

The minor components, 2,3,4,6-tetra- $O$-methyl-D-glucose and 2,6-di- $O$ methyl-D-galactose, found in the methylation analysis of the original LPS, indicate that a small part of the $\mathrm{D}$-galactose residues in the side-chains carry a terminal $\mathrm{D}$-glucose residue in the 4-position. It seems unlikely that the 2,6-di- $O$-methyl-D-galactose derivative was derived from the core, as this is assumed to contain only two $\mathrm{D}$-galactose residues, ${ }^{14}$ one being terminal and the other a chain residue. These galactose residues have already been accounted for as 2,3,4,6-tetra- $O$-methyl-D-galactose and 3,4,6-tri- $O$-methyl$\mathrm{D}$-galactose. Since it is sometimes difficult to estimate the structural significance of minor components, the presence of branched galactose residues should be regarded as tentative. The same grouping (glucose-galactose), has been found in LPS from groups $\mathrm{B}$ and $\mathrm{D}$, where it is associated with $\mathrm{O}$-factor $12_{2}$. No cross-reaction was, however, obtained between the $S$. strasbourg LPS and anti $\mathrm{O} 12_{2}$ factor sera, which fact can be explained either by differences in the anomeric nature of the D-glucose linkages or in the linkages in the main chain.

\section{EXPERIMENTAL}

The experimental methods were those used in the investigation of S. typhimurium 395 MS. A Perkin-Elmer 900 gas chromatograph with flame-ionisation detector was used. For GLC-mass spectrometry the mixture of alditol acetates dissolved in chloroform were injected into a Perkin-Elmer 270 mass spectrometer. The mass spectra were recorded at a manifold temperature of $200^{\circ}$, ionisation potential of $60 \mathrm{eV}$, ionisation current $80 \mu \mathrm{A}$ and an ion source chamber temperature of $80^{\circ}$.

Acknowledgement. The skilled technical assistance of Miss Mary Andersson, Miss Gunnel Ljunggren and Mrs. Jana Cederstrand is acknowledged. This work was supported by grants from the Swedish Medical Research Council (to A. A. L. No. B 68-48x$656-03$, and to B. L. No. B $69-13 x-2522-01)$, from the Swedish Natural Science Research Council, from Harald Jeanssons Stiftelse, from Emil and Vera Cornells Stiftelse and from Stiftelsen Sigurd och Elsa Goljes Minne.

\section{REFERENCES}

1. Nghiem, H. O., Bagdian, G. and Staub, A. M. European J. Biochem. 2 (1967) 392.

2. Hellerqvist, C. G., Lindberg, B., Svensson, S., Holme, T. and Lindberg, A. A. Acta Chem. Scand. 23 (1969) 1588.

3. Westphal, C. and Jann, K. Methods Carbohyd. Chem. 5 (1965) 83.

Acta Chem. Scand. 24 (1970) No, 4 
4. Hellerqvist, C. G., Lindberg, B., Svensson, S., Holme, T. and Lindberg, A. A. Carbohyd. Res. 8 (1968) 43.

5. Sawardeker, J. S., Sloneker, J. H. and Jeanes, A. R. Anal. Chem. 12 (1965) 1602.

6. Chizhow, O. S., Golovkina, L. S. and Wulfson, N. S. Izv. Akad. Nauk. SSSR. Ser. Khim. 19661915.

7. Krüger, L., Lüderitz, O., Strominger, J. L. and Westphal, O. Biochem. Z. 355 (1962) 548.

8. Hakomori, S. J. Biochem. (Tokyo) 55 (1964) 205.

9. Björndal, H., Lindberg, B. and Svensson, S. Acta Chem. Scand. 21 (1967) 1801.

10. Björndal, H., Lindberg, B. and Svensson, S. Carbohyd. Res. 5 (1967) 433.

11. Hellerqvist, C. G., Lindberg, B., Svensson, S., Holme, T. and Lindberg, A. A. Carbohyd. Res. 9 (1969) 237.

12. Nikaido, H., Naide, Y. and Mäkelä, P. H. Ann. N. Y. Acad. Sci. 133 (1966) 299.

13. Robbins, P. W. and Uchida, T. Biochemistry 1 (1962) 323.

14. Nikaido, H. J. Biol. Chem. 244 (1969) 2835.

Received October 1, 1969. 